\title{
Relative Efficiency in the Spatial Distribution of Physicians' Services
}

\author{
Glenda Stone and Walter O. Simmons*
}

\begin{abstract}
This paper uses health status outputs with Data Envelopment Analysis to assess the relative efficiency of the use of physician labor inputs. The trends in physician population growth are examined to see if there is a link between physician population ratios and the health status of the communities they serve. Input efficiency scores are analyzed for Michigan counties with comparable population densities over a 10-year period. Overall, approximately 47 percent of Michigan counties operated with relative input efficiency during the decade. In addition to assigning an efficiency rating, Data Envelopment Analysis also identifies the efficiency reference set. The efficiency reference set can be used to develop a composite unit that produces the same output level as the inefficient unit, employing the most efficient combination of inputs.
\end{abstract}

\section{INTRODUCTION}

The interest in increasing the number of primary care providers in the United States is driven by the need to control health care costs, improve access to services, and ensure that the distribution of providers is adequate to meet the needs of the population. Many studies have been conducted that estimate the level of efficiency in the health care sector as it relates to hospitals, nursing homes, and HMOs (Kooreman 1994; Rosenman, Siddharthan, and Ahern 1997). However, few have investigated efficiencies in public health from the counties' perspective. This study uses health data and linear programming techniques to analyze the relative efficiency of physician distribution in Michigan's 83 counties.

\section{PHYSICIAN DISTRIBUTION IN MICHIGAN}

The number of physicians engaged in direct patient care per unit of population affords some comparison of access to physicians in different areas. Data available for the years 1970 and 1985 indicate that the total active physician population grew very rapidly over this period (Marder et al. 1988). In 1970, there were 153 active nonfederal physicians per 100,000 population for the nation as a whole, but there were 133 counties that had no physician and many others that had less than 50 per 100,000 population. The ratio differences are not necessarily evidence of a shortage in physician supply since there is little agreement on what ratio would constitute an adequate supply. No one argues that all communities should have the same number of physicians per unit of population. In fact, it is widely recognized that a completely even distribution of physicians is not desirable. However, as the supply of physicians grew, some communities, particularly

"Michigan Public Health Institute, Ann Arbor, Mich.; and Department of Economics and Finance, John Carroll University, Cleveland, Ohio. 
smaller ones, continued to show characteristics of restricted access to care (MPCA and DPH 1995, p. 2).

Location theory suggests that the number of physicians in a specialty is a critical determinant of the degree to which any specialty disperses into small communities. Physicians are in a national labor market and therefore should be distributed to meet patient demand. Thus, the number of local competitors, theoretically, should adjust to equalize the net advantages of practice in different areas (Newhouse et al. 1982). ${ }^{1}$

In 1980, Michigan was the eighth most populous state in the United States. Seventy percent of its 9.2 million residents resided in urban areas and more than 80 percent made their homes in one of the state's nine metropolitan areas. ${ }^{2}$ In 1975, there were 55.2 per 100,000 population primary care physicians and 63.7 per 100,000 population specialties practicing in Michigan. By 1985, the number of primary care physicians and specialists throughout the state had risen to 72.5 per 100,000 population and 86.8 per 100,000 population, respectively (MPCA and DPH 1995).

Southeast Michigan, the state's largest metropolitan area, is believed to have the most health care providers and the greatest availability of care. In 1975 the majority of physicians in primary care located in southeast Michigan-3,196 $(67.1$ per 100,000$)$ compared to $1,855(42.2$ per 100,000$)$ in the rest of the state. Ten years later, the primary care gap had widened to $3,975(88.1$ per 100,000$)$ in southeast Michigan compared to 2,614 (57.1 per 100,000) in the rest of the state. The disparity in the ratio of physicians between southeast Michigan and the rest of the state was not the only disparity that existed; other regions, especially those that were mainly rural, had very few physicians (MPCA and DPH 1995, pp. 17-19). ${ }^{3}$ The percentage distribution of active physicians in Michigan (by county population levels) relative to the distribution of the state's general population for the years 1975 and 1985 is reflected in Table 1.

\section{TABLE 1}

Distribution of Total Physician Population Engaged in Patient Care in the State of Michigan during 1975 and 1985

\begin{tabular}{|c|c|c|c|c|}
\hline \multirow[b]{2}{*}{ County Pop. Level } & \multicolumn{2}{|c|}{1975} & \multicolumn{2}{|c|}{1985} \\
\hline & \% State Pop. & $\%$ Physician Pop. & $\%$ State Pop. & $\%$ Physician Pop \\
\hline$>1,000,000$ & 52.7 & 65.6 & 50.4 & 63.4 \\
\hline $250,000-999,999$ & 20.0 & 17.7 & 20.9 & 19.1 \\
\hline $20,000-249,999$ & 11.9 & 9.5 & 12.1 & 9.9 \\
\hline $2,500-19,999$ & 6.2 & 2.3 & 6.8 & 2.3 \\
\hline contiguous $2,500-19,999$ & 6.3 & 4.1 & 6.6 & 4.3 \\
\hline not contiguous $<2,500$ & 2.9 & 0.8 & 3.2 & 1.0 \\
\hline
\end{tabular}

${ }^{1}$ For more details on physician distribution see Roback, Randolph, and Seidman (1990); Dwyer, Barton, and Vogel (1994); Ernst and Yett (1985); and Kletke, Marder, and Silberger (1987).

${ }^{2} \mathrm{Urban}$ area is defined as cities and towns with 2,500 residents or more. The nine metropolitan areas/counties included Ann Arbor, Washtenaw County; Benton Harbor, Berrien County; Detroit, Wayne County; Flint, Genesee County; Grand Rapids-Muskegon-Holland, Kent-Muskegon-Ottawa Counties; Jackson, Jackson County; Kalamazoo-Battle Creek, Kalamazoo-Calhoun Counties; Lansing-East Lansing, Ingham County; and SaginawBay City-Midland, Saginaw-Bay-Midland Counties.

3Southeast Michigan refers to the counties of Livingston, Macomb, Monroe, Oakland, St. Clair, Washtenaw, and Wayne. 


\section{DATA DESCRIPTION}

The data used in this study consist of medical input and health status output variables from the Bureau of Health Professions Area Resource File 1940-1990 (BHPARF), Michigan's Department of Public Health (MDPH), and Primary Health Care Profile of Michigan (PHCPM). BHPARF is a county-based data file summarizing secondary data from a wide variety of sources into a single file to facilitate health analysis. Variables include population, number of hospital beds, and the number of nonfederal physicians engaged in direct patient care in 38 specialties. Reported cases of infant mortality were obtained from the MDPH, Division of Vital Statistics. Reported cases of disease leading to death were obtained from PHCPM. Observations from 70 of the 83 Michigan counties for 1975 and 1985 are used in this study. Thirteen counties were excluded because of missing input and output measures.

\section{EMPIRICAL FRAMEWORK}

To assess the relative efficiency of the use of physician labor inputs, a method of Data Envelopment Analysis (DEA) is employed. DEA locates technical or Pareto inefficiencies in a manner more consistent with economic theory than econometric regression techniques. That is, DEA measures efficiency compared with best-performing counties rather than based on a mean or central tendency relationship that reflects a mixture of efficient and inefficient behavior. It is particularly useful in public health applications because it can simultaneously accommodate multiple outputs and inputs and does not require specific knowledge of the efficient absolute or relative amount of inputs required for each measure of health output (Banker, Charnes, and Cooper 1984). A limitation of DEA is that it can only be used to compare units, as it locates only relatively inefficient units. Hence, it cannot identify all inefficient counties because all counties in the data set may be inefficient. However, this limitation extends to regression and ratio analysis techniques as they have been used to date. ${ }^{4}$

The DEA method has been utilized in measuring efficiency outcomes in a variety of health care applications. One application of DEA in healthcare is provided by Rosenman, Siddharthan, and Ahern (1997). They used DEA to measure relative output efficiencies of HMOs in the state of Florida. The average HMO was found to be relatively inefficient, with a 67 percent rating compared to the theoretical optimum. The authors calculated the efficiency of each HMO by organizational type and ownership. Staff models in which physicians are paid on a capitated basis were most efficient. For-profit Florida HMOs were found to be more efficient than nonprofit Florida HMOs.

Kooreman (1994) used DEA to analyze the technical efficiency of Dutch nursing homes with respect to the use of labor inputs. His inputs include six types of labor: medical doctors, nurses, nurse trainees, therapists, general staff, and other personnel. A vector of four output types based on the number of patients ${ }^{4}$ Ritchic (1996) compares different DEA models in terms of their potential to generate a quantitative measure of the degree of inefficiency. For other methods of measurements see Lewin and Lovell (1990). 
distinguishes between physically disabled patients and patients with psychogeriatric disability, as well as between full-care and day care patients. Kooreman (1994) found 50 percent of the nursing homes to be fully efficient, according to the theoretically preferred frontier with constant or decreasing returns to scale.

Considering all counties in the set to be evaluated, each county is assigned to a subset that represents a best comparison group for effecting an evaluation of its performance on all inputs and outputs (Butler and Johnson 1996). By being relatively efficient, a county is operating as efficiently as any other county in the comparison group for the specified inputs and outputs. By being inefficient, the county performance is inferior to others in the group. DEA provides an empirical assessment of the performance of each county without requiring explicit assumptions that limit the functional forms, which relate inputs and outputs. This advantage over single-output models also expands the traditional scope of efficiency analysis by comparing counties, or other decision-making units, with similar inputs and outputs while providing a single measure of efficiency, which represents a ratio of outputs to inputs.

DEA is a fractional program solved as a linear program for each of the " $\mathrm{c}$ " counties using an iterative technique. The efficiency ratio of each of the " $c$ " counties is maximized in the objective function and constrained to take a value less than or equal to one. The following model, known as the CCR Ratio Model, contains the mathematical programming format through which such a problem may be solved.

The following maximization problem is solved $c$ times, once for each county. Let $o$ represent any one of the counties. For this county, vectors $u=\left(u_{1}, \ldots, u_{s}\right)$ and $\mathrm{v}=\left(\mathrm{v}_{1}, \ldots, \mathrm{v}_{\mathrm{m}}\right)$ are chosen to solve the following problem.

$$
\operatorname{MAXE} E_{o}=\left[\sum_{r=1}^{s} u_{r} y_{r o}\right] /\left[\sum_{i=1}^{m} v_{i} x_{i o}\right]
$$

subject to:

$$
\left[\sum_{r=1}^{s} u_{r} y_{r j}\right] /\left[\sum_{i=1}^{m} v_{i j} x_{i j}\right] \leq 1 \quad j=1, \ldots, c,
$$

where:

$0=$ the county being assessed from the set of c counties;

$s=$ the number of outputs being evaluated in the county;

$\mathrm{m}=$ the number of inputs in the county;

$\mathrm{u}_{\mathrm{r}}=$ the weight of the output value;

$\mathrm{y}_{\mathrm{rj}}=$ observed output $\mathrm{r}$ in county $\mathrm{j}$ (assume nonnegative value);

$v_{i}=$ the weight of the input value; and

$x_{i j}=$ observed input $i$ in county $j$ (assume nonnegative value).

The vectors $(u, v)$ with variables $u_{r}, v_{i} \geq 0$ as components are selected to maximize the ratio in the objective of Equation 1. The ratio in Equation 1 is an end product of the $x_{i j}$ and $y_{r j}$, which are constants that represent the observed values 
of the $i=1, \ldots, m$ inputs used and $r=1, \ldots$, s outputs produced by each of $j=1, \ldots$, c counties. County o, as represented in the objective of Equation 1, is the county to be evaluated from these data by maximizing its score relative to the ratios for the entire collection of county $j, j=1, \ldots, c$-with county $o$ included in the objective as well as the constraint. $y_{0}$ and $y_{j}$ represent "virtual outputs" and $x_{0}$ and $x_{j}$ represent "virtual inputs." Because $y_{j} / x_{j}$ is maximal over the set $j=1, \ldots, c$, which includes $j=0$, we have $y_{0} / x_{0} \leq y_{j} / x_{j}$. The above ratios therefore have a maximum value of unity and this is achievable if and only if county o's performance is not bettered by some other county.

The first step in establishing a health status production frontier is determining the appropriate input and output factors. These factors need only be measurable in their natural physical units. A homogeneous measurement unit is not required. Output factors in this study are a county's health status. Health status indicators provide a snapshot of the well-being of a community's residents. Two health status indicators are used in this study. One is the inverse of the infant mortality rate. Michigan's infant mortality rate was 1.65 percent in 1975 and 1.14 percent in 1985. The other is derived from the sum of the reported number of cases of bronchitis, emphysema, and asthma; cirrhosis of the liver; ischemic heart disease; infectious and parasitic disease; and influenza and pneumonia for each county during 1975 and 1985. The number of cases as a percentage of total county population was inverted to determine the percentage of the population unaffected by these maladies. The unaffected percentage of the population, the Healthy Resident Rate, is used as a second measure of health status in this study.

Three inputs are used in this study. They include numbers of physicians (primary and specialty care), and the number of hospital beds. Primary health care describes a basic level of health care services, including disease prevention services. These services are typically comprehensive and provide continuity of care. Ideally, they are community oriented and coordinated: the primary health care provider serves as the point of access into the health care system. Primary care services are most often provided by general practitioners, family practitioners, internists, pediatricians, obstetricians/gynecologists, as well as other midlevel providers. Midlevel providers include nurse practitioners, physician assistants, and certified nurse midwives. The growing role that nurse midwives, physician assistants, and nurse practitioners play in providing primary care services confounds the issue of the appropriate supply of total physicians and primary care physicians in the United States (Public Sector Consultants 1996). Hospital beds are included as a proxy for capital inputs.

From 1975 to 1985, there was a relative decrease in the number of primary care physicians as more physicians entered specialty fields. Consequently, patients entered the health care system at costly secondary and tertiary stages of illness. Primary care expands access to health care and is cost effective. Early intervention, prevention, and patient management are basic components of primary care delivery. 


\section{RESULTS}

Determining whether a county could have done better in terms of health status is a result of either: (a) achieving the same level of health status in the population with fewer or more efficient use of resources (input efficiency); or (b) achieving a higher level of health status without incurring an increase in resources (output efficiency).

This paper examines the first of these two separate problems. The DEA results for counties in rural/urban area $2(250,000$ - 999,999 population) during 1975 are summarized in Table 2. The results indicate that Saginaw, Ottawa, Kent, and Genesee counties are relatively inefficient compared with the other counties in the data set; that is, they have an input efficiency rating of less than 1.0. The efficiency ratings suggest that, compared with other counties in this group, the inefficient counties should be able to produce their same level of health status (outputs) with fewer inputs.

\section{TABLE 2}

1975 DEA Input Efficiency

Michigan Counties with 250,000 - 999,999 Residents

\begin{tabular}{lcccc}
\hline & DEA & DEA Results & Input \\
Input & $\begin{array}{c}\text { Input } \\
\text { Efficiency } \\
\text { Rating }\end{array}$ & $\begin{array}{c}\text { Effiency } \\
\text { Reference } \\
\text { Set }\end{array}$ & $\begin{array}{c}\text { Infant } \\
\text { Survival } \\
\text { Rate }\end{array}$ & $\begin{array}{c}\text { Healthy } \\
\text { Resident } \\
\text { Rate }\end{array}$ \\
\hline County & 1.0 & - & .9948 & .9974 \\
Clinton & 0.64 & Clinton & .9846 & .9969 \\
Saginaw & 0.45 & Clinton, Midland & .9893 & .9975 \\
Ottawa & 1.0 & - & .9839 & .9979 \\
Midland & 0.28 & Clinton & .9793 & .9969 \\
Kent & 1.0 & - & .9835 & .9979 \\
Ingham & 1.0 & - & .9894 & .9968 \\
Eaton & 1.0 & .9863 & .9968 \\
Bay & 0.41 & Clinton & .9809 & .9972 \\
Genesee & & & & \\
\hline
\end{tabular}

The meaning of the inefficient rating derived from DEA can be understood by examining the results for Ottawa County. DEA indicates that Ottawa County is inefficient, with an efficiency rating of 0.45 based on a comparison of Ottawa County with all nine counties in rural/urban area 2. Generally, this means that Ottawa County should be able to produce its actual output level using 55 percent $[(1.00-0.45) \times 100]$ less of each input. More specifically, DEA indicates that the inefficiency was located and measured by comparing Ottawa County with its efficiency reference set Clinton and Midland counties, noted in Table 2.

The efficiency reference set is the group of counties against which DEA located the inefficient counties and the magnitude of the inefficiency. This information is a direct output of DEA. By identifying the efficiency reference set, DEA allows one to focus on a subset of these counties to understand better the inefficiencies present. This comparison is illustrated in Table 3 , which indicates that a weighted composite of the efficiency reference set counties would yield a hypothetical county that 
produces as much or more outputs as the inefficient Ottawa County but also that uses fewer inputs than Ottawa County. In this example, the composite is constructed by applying the weights (from the DEA linear program) of 0.698 and 0.302 , respectively, to the actual outputs and inputs of Clinton and Midland counties. Columns 3, 4, and 5 of Table 3 indicate that a combination of the actual factors employed in these two counties would result in a hypothetical county that would use 19 primary MDs, 13 specialty MDs, and 134 beds to produce the same level of health status produced by inefficient Ottawa County.

\section{TABLE 3}

1975 Comparison of Ottawa County with its Input Efficiency Reference Set Counties

(1)

\begin{tabular}{lrrrrr} 
& $\begin{array}{c}\text { Clinton } \\
\text { County }\end{array}$ & $\begin{array}{c}\text { Midland } \\
\text { County }\end{array}$ & $\begin{array}{c}\text { Compostie } \\
(0.698+0.302)\end{array}$ & $\begin{array}{c}\text { Ottawa } \\
\text { County } \\
(1975 \text { Actual })\end{array}$ & $\begin{array}{c}\text { Ottawa - } \\
\text { Composite } \\
(4)-(3)\end{array}$ \\
\hline Primary MDs & $(0.698)^{n} 5$ & $(0.302)^{\mathrm{a}} 51$ & 19 & 42 & 23 \\
Specialty MDs & 2 & 39 & 13 & 42 & 29 \\
Number of Beds & 81 & 255 & 134 & 374 & 140 \\
\hline
\end{tabular}

${ }^{a}$ An explanation of the derivation of DEA variable weights is provided in Banker, Charnes, and Cooper (1984).

By 1985, the overall input efficiency ratings in rural/urban area 2 had decreased, although the relative rankings remained virtually unchanged. The 1985 results in rural/urban area 2 are presented in Table 4. Reexamining the results for Ottawa County, DEA indicates that while Ottawa County remains inefficient its input efficiency rating improved from the 1975 level of 0.45 to 0.654 in 1985. Ottawa County should then be able to produce its 1985 actual output level using 34.6 percent less of each input. Additionally, in 1985 Ottawa is compared to an efficiency reference set that includes Eaton County, as well as Clinton and Midland counties.

\section{TABLE 4}

1985 DEA Input Efficiency Michigan Counties with 250,000 - 999,999 Residents

\begin{tabular}{lcccc}
\hline County & $\begin{array}{c}\text { DEA Input } \\
\text { Efficiency } \\
\text { Rating }\end{array}$ & $\begin{array}{c}\text { DEA Results } \\
\text { Input } \\
\text { Efficiency } \\
\text { Reference Set }\end{array}$ & $\begin{array}{c}\text { Infant } \\
\text { Survival } \\
\text { Rate }\end{array}$ & $\begin{array}{c}\text { Healthy } \\
\text { Resident } \\
\text { Rate }\end{array}$ \\
\hline Clinton & 1.0 & - & .9892 & .9974 \\
Saginaw & 0.40 & Clinton & .9844 & .9969 \\
Ottawa & 0.65 & Clinton, Midland, Eaton & .9923 & .9976 \\
Midland & 1.0 & - & .9961 & .9979 \\
Kent & 0.18 & Clinton, Midland, Eaton & .9916 & .9976 \\
Ingham & 1.0 & - & .9882 & .9979 \\
Eaton & 1.0 & - & .9872 & .9979 \\
Bay & 0.31 & Clinton, Midland & .9894 & .9964 \\
Genesee & 0.26 & Clinton & .9868 & .9972 \\
\hline
\end{tabular}

Table 5 presents the input efficiency ratings for the period. The overall input efficiency within the state of Michigan was around 79 percent in 1975 and 73 percent in 1985. In 1975, 49 percent of the counties analyzed operated with 
relative input efficiency according to the theoretically preferred frontier with variable returns to scale. The nonefficient counties used on average roughly 21 percent more inputs per unit of output than the efficient counties. By 1985, 47 percent of the counties operated with relative input efficiency. The nonefficient counties used 27 percent more inputs per unit of output that year.

TABLE 5

1975 and 1985 Input Efficiency Ratings by County Population Density $(n=70)$

\begin{tabular}{|c|c|c|c|c|c|c|}
\hline & \multicolumn{3}{|c|}{1975 Efficiency Ratings } & \multicolumn{3}{|c|}{1985 Efficiency Ratings } \\
\hline & $\begin{array}{c}\text { Mean } \\
\text { efficiency (\%) } \\
\text { (SD) }\end{array}$ & $\begin{array}{l}\text { Min. } \\
(\%)\end{array}$ & $\underset{(\%)}{\operatorname{Max} .}$ & $\begin{array}{c}\text { Mean } \\
\text { efficiency (\%) } \\
\text { (SD) }\end{array}$ & $\begin{array}{l}\operatorname{Max} \\
(\%)\end{array}$ & $\begin{array}{l}\text { Min } \\
(\%)\end{array}$ \\
\hline All Counties & $\begin{array}{l}78.68 \\
(28.72)\end{array}$ & 12.5 & 100 & $\begin{array}{c}73.14 \\
(32.53)\end{array}$ & 10.9 & 100 \\
\hline $\begin{array}{l}\geq 1,000,000 \\
\quad(n=8)\end{array}$ & $\begin{array}{l}72.58 \\
(44.99)\end{array}$ & 12.5 & 100 & $\begin{array}{l}73.54 \\
(46.87)\end{array}$ & 19.4 & 100 \\
\hline $\begin{array}{l}250,000-999,999 \\
(n=9)\end{array}$ & $\begin{array}{l}75.33 \\
(43.86)\end{array}$ & 28.0 & 100 & $\begin{array}{l}64.53 \\
(44.41)\end{array}$ & 18.0 & 100 \\
\hline $\begin{array}{c}20,000-249,999 \\
(n=9)\end{array}$ & $\begin{array}{l}71.98 \\
(28.69)\end{array}$ & 30.9 & 100 & $\begin{array}{c}62.35 \\
(37.02)\end{array}$ & 10.9 & 100 \\
\hline $\begin{array}{l}2,500-19,999 \\
\text { contiguous }(n=12)\end{array}$ & $\begin{array}{l}86.92 \\
(18.38)\end{array}$ & 44.7 & 100 & $\begin{array}{c}81.26 \\
(24.67)\end{array}$ & 37.1 & 100 \\
\hline $\begin{array}{l}2,500-19,999 \\
\text { not contiguous }(n=21)\end{array}$ & $\begin{array}{c}72.91 \\
(28.11)\end{array}$ & 25.9 & 100 & $\begin{array}{l}62.49 \\
(34.06)\end{array}$ & 14.2 & 100 \\
\hline $\begin{array}{l}\leq 2,500 \\
\quad(n=11)\end{array}$ & $\begin{array}{c}92.37 \\
(11.13)\end{array}$ & 70.2 & 100 & $\begin{array}{l}94.65 \\
(10.04)\end{array}$ & 56.0 & 100 \\
\hline
\end{tabular}

The counties with the lowest population density (less than 2,500) experienced the highest input efficiency ratings. In 1975, approximately 55 percent of these counties had relative input efficiency. The mean efficiency for this group was 92.37 percent. By 1985, 63.6 percent of these counties had achieved relative efficiency and the mean efficiency had increased to 94.65 percent.

Seven of the eight counties with population density of 1 million and more comprise southeast Michigan. In 1975, 50 percent of the eight most densely populated counties in the state were relatively input efficient. Their 1975 mean input efficiency was 72.58 percent. Ten years later, the percentage of relatively input efficient counties in this group remained unchanged at 50 percent. However, the mean input efficiency increased to 73.54 percent. During the 1975-1985 decade, the two groupings containing the most densely populated counties and the least densely populated counties were the only ones to achieve an increase in their mean input efficiency ratings.

\section{IMPLICATION AND CONCLUSION}

Timely and effective medical treatments are critical to the preservation of health, both individually and as a community. Trends in physician population growth and the relative efficiency of the use of physician's labor inputs are important measures to the health care community. Input efficiency scores (based on Data Envelopment Analysis) analyzed for Michigan counties with comparable 
population densities over a 10 -year period provide an important link between physician population ratios and the health care status of the communities they serve. This information is of use in assisting communities to identify areas where health care needs are not being met. Relative efficiency rankings from communities with similar population densities and demographic characteristics can be compared and specific input levels can be targeted to achieve public health goals.

Despite its benefits, DEA limits the interpretation of efficiency to that related to production. It provides no insight concerning the correct amount of health care being provided to the correct number and mix of residents. An important aspect of efficiency analysis in health care is the quality of care patients receive. To the extent that higher quality requires more inputs, a high output efficiency score may simply reflect poor quality of care. To determine the extent of this relationship in a public health forum requires data on quality of care as well as the needs of the population.

This study contributes to the health economics literature by providing a link between physician distribution and the production of health status. Another significant feature of this study is the grouping of counties with similar population densities to construct production frontiers. While only Michigan health data was used in this analysis, the study has broader implications because the methodology is applicable to communities in every state. The largest possible efficiency is determined by the state itself. Consequently, DEA is not able to detect a possible inefficiency of the state as a whole. However, considering how difficult it is to find an external standard of efficiency in a public health setting, DEA proves to be a useful tool.

\section{REFERENCES}

Banker, R.D., A. Charnes, and W.W. Cooper. "Some Models for Estimating Technical and Scale Inefficiencies in Data Envelopment Analysis." Management Science 30 (9) (1984), 1078-1092.

Butler, T.W., and W.W. Johnson. "Efficiency Evaluation of Michigan Prisons Using Data Envelopment Analysis." Wayne State University, 1996.

Cooper, J.K., K. Heald, M. Samuels, and S. Coleman. "Rural or Urban Practice: Factors Influencing the Location Decision of Primary Care Physicians." Inquiry 12 (1975), 18-25.

Dwyer, J.W., A.J. Barton, and W.B. Vogel. "Area of Residence and the Risk of Institutionalization." Journal of Gerontology 49 (2) (1994), S75-S84.

Ernst, R.L., and D.E. Yett. Physician Location and Specialty Choice. Ann Arbor, Mich.: Health Administration Press, 1985.

Kletke, P.R., W.D. Marder, and A.B. Silberger. The Demographics of Physician Supply: Trends and Projections. Chicago: American Medical Association, 1987.

Kooreman, P. "Nursing Home Care in The Netherlands: A Nonparametric Efficiency Analysis." Journal of Health Economics 13 (1994), 301-316.

Lewin, A.Y., and C.A.K. Lovell. "Frontier Analysis-Parametric and Nonparametric Approaches." Journal of Econometrics 46 (1990), 3-5. 
Marder, W.D., P.R. Kletke, A.B. Silberger, and R.J. Willke. Physician Supply and Utilization by Specialty: Trends and Projections. Chicago: American Medical Association, 1988.

Michigan Primary Care Association and Michigan Department of Public Health (MPCA and DPH). Primary Health Care Profile of Michigan. Okemos, Mich., 1995.

Newhouse, J.P., A.P. Williams, B.W. Bennett, and W.B. Schwartz. How Have Location Patterns of Physicians Affected the Availability of Medical Services. Santa Monica, Calif.: Rand Corporation, 1982.

Public Sector Consultants, Inc. Health Professions Workforce in Michigan: State of the State. Lansing, Mich., 1996.

Ritchic, P.C. "Choice of Metric in the Measurement of Relative Productive Efficiency." International Journal of Production Economics 46-47 (1996), 433-439.

Roback, G., L. Randolph, and B. Seidman. Physician Characteristics and Distribution in the U.S. Chicago: American Medical Association, 1990.

Rosenman, R., K. Siddharthan, and M. Ahern. "Output Efficiency of Health Maintenance Organizations in Florida." Health Economics 6 (1997), 295-302. 